\title{
Synthesis of two new discotic liquid crystals with 1,3,4- oxadiazole as functional group
}

\author{
Edivandro Girotto, André A. Vieira, Fernando Molin, Hugo Gallardo* \\ Departamento de Química, Universidade Federal de Santa Catarina-UFSC, 88040-900 Florianópolis,SC, \\ Brasil \\ *corresponding author e-mail: hugo@qmc.ufsc.br
}

Keywords: liquid crystal, 1,3,4-oxadiazole, devices

\section{INTRODUCTION}

Since the first record of discotic liquid crystals (DLCs) by Chandrasekhar et al. in $1977^{1}$, the synthesis and studies of these materials have been increased exponentially. They present remarkable charge transport properties including electronic conductivity $^{2}$, and thus several devices have been built based on these eletrooptical properties, such as solar cells, active components for image and data treatment, among others ${ }^{3}$. Considering the properties above mentioned, two new molecules were synthesized (5 and 6), which exhibit properties characteristics of liquid crystalline mesogenic with discotic anisometry.

\section{RESULTS AND DISCUSSION}

The synthetic route of targets compounds (DLCs) was carried out as described on Scheme 1.

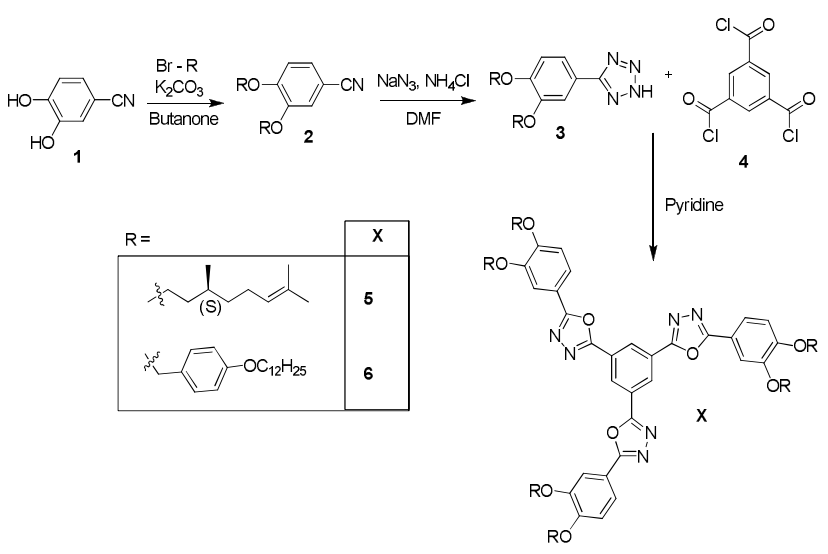

Scheme 1. Synthesis of 1,3,4-oxadiazole derivatives.

The synthetic route for the preparation of compounds 5 and 6 was same for both, changing only the $R$ group. Initially the 3,4dihydroxybenzonitrile was alkylated with appropriated $\mathrm{R}$ group to produce compound $\mathbf{2}$, which reacted with sodium azide and ammonium chloride in dry DMF to form tetrazole $\mathbf{3}$. The compound $\mathbf{3}$ was reacted with triacid chloride 4 (previously prepared from 1,3,5-benzenetricarboxylic acid in thionyl chloride), in pyridine, forming the desired compounds 5 and 6 . The synthesis of alkoxybenzylbromide 10, is presented on Scheme 2. The hydroxy group in compound 7 was alkylated, and the corresponding esther group was reduced using $\mathrm{LiAlH}_{4}$ in THF to give 9, which reacted with $\mathrm{HBr}$ to form the bromide $\mathbf{1 0}$.

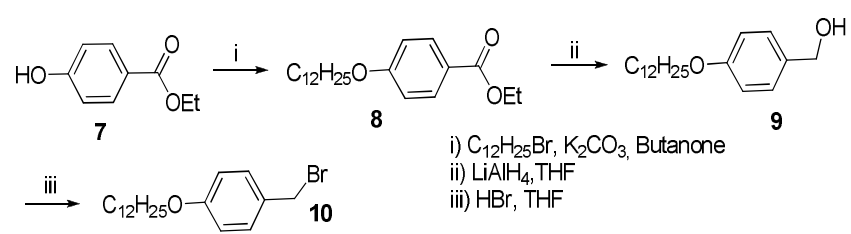

Scheme 2. Synthesis of substituent R (10) of compound 6.

All compounds were characterized by ${ }^{1} \mathrm{H}$ and ${ }^{13} \mathrm{C}$ NMR spectroscopy. These final compounds $\mathbf{5}$ and $\mathbf{6}$ showed liquid crystalline properties. Compound $\mathbf{5}$ was characterized by polarized light optical microscopy (POM) and differential scanning calorimetry (DSC). This compound is liquid crystal at room temperature, presenting isotropic phase at $121{ }^{0} \mathrm{C}$, and exhibiting columnar mesophase characteristics of DLC's. The analysis of mesophases of compound 6 are under investigation.

\section{CONCLUSION}

Two new compounds, 5 and 6, 1,3,4-oxadiazole derivatives, with liquid crystalline properties were synthesized and both showed luminescent properties.

\section{ACKNOWLEDGEMENTS}

UFSC, CAPES, CNPq, INCT-Cat and FAPESC

\section{REFERENCES}

${ }^{1}$ H. Lee, J. H.; Han, M. J. Tetrahedron Lett.. 2005, 46, 7143

${ }^{2}$ Cristiano, R.; Gallardo, H. J. Liq. Cryst. 2005, 32, 7

3 Ghedini, M.; Pucci, D. J. Inorg. Chem. Comm.2007,10, 243. 